Article

\title{
A New Approach for Determination of the Botanical Origin of Monofloral Bee Honey, Combining Mineral Content, Physicochemical Parameters, and Self-Organizing Maps
}

\author{
Tsvetomil Voyslavov $^{1, * \mathbb{D}}$, Elisaveta Mladenova ${ }^{1}(\mathbb{D})$ and Ralitsa Balkanska ${ }^{2} \mathbb{D}$ \\ 1 Department of Analytical Chemistry, Faculty of Chemistry and Pharmacy, \\ Sofia University "St. Kliment Ohridski”, 1164 Sofia, Bulgaria; elimladenova@chem.uni-sofia.bg \\ 2 Department of Special Branches, Institute of Animal Science, 2232 Kostinbrod, Bulgaria; \\ r.balkanska@gmail.com \\ * Correspondence: voyslavov@abv.bg
}

check for

updates

Citation: Voyslavov, T.; Mladenova,

E.; Balkanska, R. A New Approach

for Determination of the Botanical

Origin of Monofloral Bee Honey,

Combining Mineral Content,

Physicochemical Parameters, and

Self-Organizing Maps. Molecules 2021,

26,7219. https://doi.org/10.3390/

molecules26237219

Academic Editor: Gavino Sanna

Received: 30 October 2021

Accepted: 25 November 2021

Published: 28 November 2021

Publisher's Note: MDPI stays neutral with regard to jurisdictional claims in published maps and institutional affiliations.

\begin{abstract}
A new approach for the botanical origin determination of monofloral bee honey is developed. The methodology combines mineral content and physicochemical parameters determination with intelligent statistics such as self-organizing maps (SOMs). A total of 62 monofloral bee honey samples were analysed, including 31 linden, 14 rapeseed, 13 sunflower, and 4 acacia. All of them were harvested in 2018 and 2019 from trusted beekeepers, after confirming their botanical origin, using melissopalynological analysis. Nine physicochemical parameters were determined, including colour, water content, $\mathrm{pH}$, electrical conductivity, hydroxymethylfurfural content, diastase activity, specific optical rotation, invertase activity, and proline. The content of thirty chemical elements (Ag, Al, As, B, Ba, Bi, Ca, Cd, Co, Cr, Cs, Cu, Fe, Ga, In, K, Li, Mg, Mn, Na, Ni, P, Pb, Rb, S, Se, $\mathrm{Sr}, \mathrm{Te}, \mathrm{V}$, and $\mathrm{Zn}$ ) was measured using ICP-OES, ICP-MS, and FAAS as instrumental techniques. The visualisation of the SOMs shows an excellent separation of honey samples in five well-defined clusters-linden, rapeseed, acacia, sunflower, and polyfloral honey-using the following set of 16 descriptors: diastase activity, hydroxymethylfurfural content, invertase activity, $\mathrm{pH}$, specific optical rotation, water content, $\mathrm{Al}, \mathrm{B}, \mathrm{Cr}, \mathrm{Cs}, \mathrm{K}, \mathrm{Na}, \mathrm{Ni}, \mathrm{Rb}, \mathrm{V}$, and $\mathrm{Zn}$.
\end{abstract}

Keywords: self-organizing maps; botanical origin determination; physicochemical parameters; chemical elements; melissopalynological analysis

\section{Introduction}

Generally, honey is a multicomponent product, which contains, as its main substituents, carbohydrates (70-80\%), water, small amounts of enzymes, proteins, organic acids, different chemical elements, vitamins, lipids, aromatic compounds, and biologically active substances. The mineral content of honey varies widely-from $0.02 \%$ in pale honey to $1.03 \%$ in dark honey [1]. The amount of all of the constituent components in bee honey depends on many factors, some of which are related to the type of bee that produced it (in Bulgaria, the bees Apis mellifera are breeding); others relate to the competence, techniques, and good practices of the beekeeper and honey producer. The type of plant from which the bees collect their nectar, and its ability to absorb minerals from the soil, and the climate and degree of the anthropogenic impact of the area, however, have the most noticeable impact [2]. The complexity of all of these factors makes choosing a methodical approach to identifying the different types of monofloral honeys by botanical origin and authenticity difficult [3,4].

Honey is a natural product that has been used as food and medicine since ancient times. It is produced by the processing of nectar by honeybees. Depending on its origin, honey is divided into monofloral (obtained predominantly from the nectar of one plant species) and polyfloral (obtained from different types of floral nectar). Different types of 
monofloral honey vary greatly in colour, aroma, and flavour. The physicochemical properties and honey composition of a certain kind of monofloral honey can also vary within itself, depending on seasonal weather conditions or geographical origin [5,6]. Monofloral honey, predominantly containing pollen from one plant species, is of higher quality, and is therefore more expensive than its polyfloral counterparts, which reinforces the need for an appropriate analysis technique, through which identifying the authenticity of monofloral honey would be made possible.

In order for a product to be labelled as honey, certain requirements, as described in Directive 2001/110/EC [7], such as the values of certain physicochemical parameters and/or pollen content of the honey, in order for it to be defined as monofloral $[8,9]$, need to be met.

Systematic studies have been carried out on the ability to use a combination of different methods for proving the botanical origin of honey and potential fakes. The efforts are directed towards the selection of the appropriate descriptors, which allow for the preparation of a maximally authentic identification. It has been found that the determination of a single component on its own (chemical and physicochemical properties), such as a large number of chemical elements, hydroxymethylfurfural, water content, enzyme activity, mono- and disaccharides, nitrogen-containing compounds, or residues after antibiotic treatment of the bees, does not carry enough information on the geographical and botanical origin of honey [6]. On the contrary, determining the content of certain trace elements, and the ratios between the contents of certain elements, as well as the existence of a correlation between certain physicochemical parameters and the amounts of certain elements, are more reliable identifiers which could be used to classify different types of monofloral honey.

The application of these methods naturally requires the application of appropriate statistical analyses-cluster analysis [10-24], principal component analysis [11-14,16,17,21-23,25-27], etc. Combining the results of classical analytical methods for determining components in various types of monofloral honey with intelligent multivariate analyses, such as neural networks, is a new opportunity for the reliable identification of the botanical $[17,20,22]$ and geographical $[14,20,28]$ origin of monofloral honey. Kohonen self-organizing maps are one of these kinds of networks which are used for the botanical identification of different food products [29]; they could also be used for determining the botanical origin of different sorts of monofloral bee honey.

The bee honey which is produced in the territory of Bulgaria satisfies the needs of Bulgaria's internal market. In addition, a big part of the production is exported to other countries in the European Union, as well as other countries outside of the European Union. This means that, regarding trade relations, honey production is an important part of the gross domestic product of Bulgaria. The bee honey produced in Bulgaria is mainly monofloral (e.g., from rapeseed, sunflower, thistle, linden, acacia, or coriander plants) [30]. The monofloral origin of the honey determines its higher price. Nowadays, consumers want to be sure about the definite origin of the products which they consume, due to which researchers are faced by a challenge-finding appropriate identifiers which allow for the reliable determination of fakes, false origin, and misleading statements about the authenticity of foods' composition, which is an extremely difficult analytical task.

Traditionally, the botanical origin of monofloral honey has been ascertained by melissopalynological analysis-the pollen content is determined by microscopic examination, which is costly, time consuming, and requires personnel with high levels of expertise [8]. This in turn provokes the aim of this research-to develop a new methodological approach for the botanical origin determination of Bulgarian monofloral bee honey, which can be used as a suitable alternative to the traditional and expensive pollen analysis. This can be achieved by investigating the mineral content of traditional kinds of Bulgarian monofloral honey (e.g., linden, acacia, sunflower, coriander, lavender, thistle) and looking for a correlation or a common pattern between the mineral content, different physicochemical parameters, and the botanical origin of the honey. 


\section{Results}

\subsection{Samples}

The bee honey samples used in the study were obtained from reliable producers, members of The Bulgarian Honey Producers Association, and were harvested in 2018 and 2019. Thirty-one linden honey samples were used-seventeen from 2018 and fourteen from 2019. Eight rapeseed samples from 2018 were used, and six from 2019. As a result of unfavourable weather conditions during the summer of 2018 in Bulgaria, a decline in sunflower honey harvesting was reported, which is why only thirteen such samples from 2019 were used. In addition, only four acacia samples were used-two from 2018 and two from 2019-as a result of the rainy spring seasons of the aforementioned years, adding up to a total number of sixty-two monofloral bee honey samples. The botanical origin of all of the collected samples was preliminarily stated by the beekeepers and confirmed (excluding two sunflower honey samples) through melissopalynological analysis. The honey samples were kept in dark, room temperature $\left(20\right.$ to $\left.25^{\circ} \mathrm{C}\right)$ conditions, before conducting any analyses.

\subsection{Basic Statistics}

The data matrix, comprising all 39 variables (physicochemical parameters and minerals), and all honey samples, was constructed using the data presented in Tables S1-S4. The raw data obtained from the four acacia honey samples are presented in Table S1. The basic statistics ( $\min$, max, mean, and standard deviation values) of all of the monofloral bee honey samples (excluding acacia), separated by botanical origin (linden, sunflower, rapeseed), for the two monitored harvesting years (excluding sunflower), are presented in Table S2 (linden), Table S3 (sunflower), and Table S4 (rapeseed).

\subsection{Set of Descriptors}

Using the data for mineral content and physicochemical parameters of the analysed honey samples, and the technique of self-organizing maps, the optimal set of descriptors was constructed. The indicator used for deciding whether to include the variable (mineral or physicochemical parameter) in the optimal set of descriptors was the successful separation by botanical origin of the honey samples. The set of descriptors was made by using a step-by-step reduction approach of the variables, all the while following the successful separation rule. The HIT diagram, associated with the first SOM, including all variables, is presented in Figure 1. A very good separation of honey samples in four well-defined clusters is observed: linden, rapeseed, acacia, and sunflower.

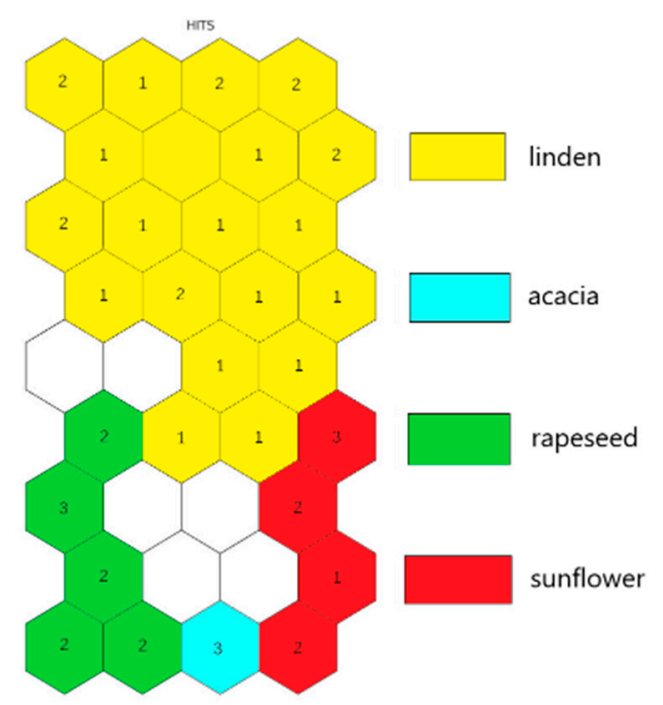

Figure 1. The HIT diagram of training set with all variables. 
The grouping of variable planes (Figure 2) shows five main clusters of correlated variables. Element $\mathrm{B}$ has a specific location and forms a cluster by itself. The elements $\mathrm{Ca}$ and Cs also form a cluster, while the other variables are grouped in three large clusters. This observation illustrates the similar distribution of the parameters within each group of the honey samples.

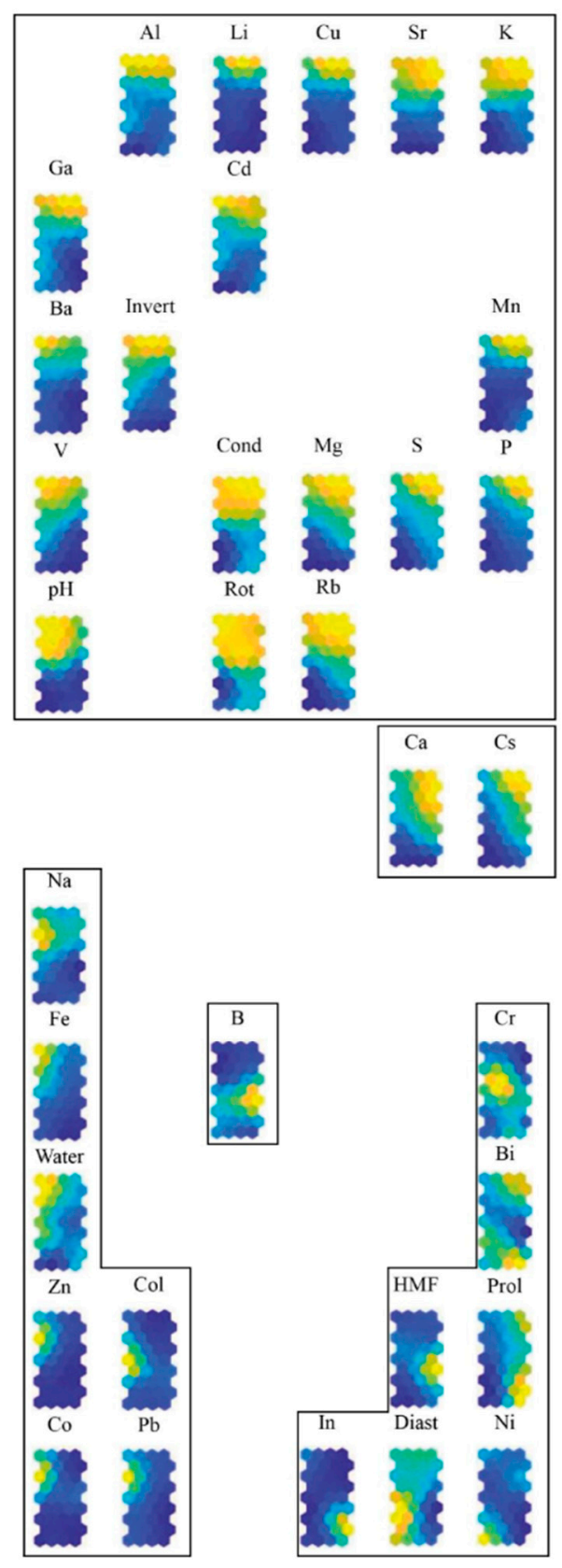

Figure 2. Ordering of variable planes in five main clusters. The abbreviations of the analytes are described in Section 4.3.

After the step-by-step reduction of the number of input parameters, while maintaining the good separation of the samples into four different clusters (Figure 3) by botanical origin, the set of descriptors was constructed. The set is formed of sixteen variables: Diast, HMF, Invert, $\mathrm{pH}$, Rot, Water, $\mathrm{Al}, \mathrm{B}, \mathrm{Cr}, \mathrm{Cs}, \mathrm{K}, \mathrm{Na}, \mathrm{Ni}, \mathrm{Rb}, \mathrm{V}$, and $\mathrm{Zn}$. 


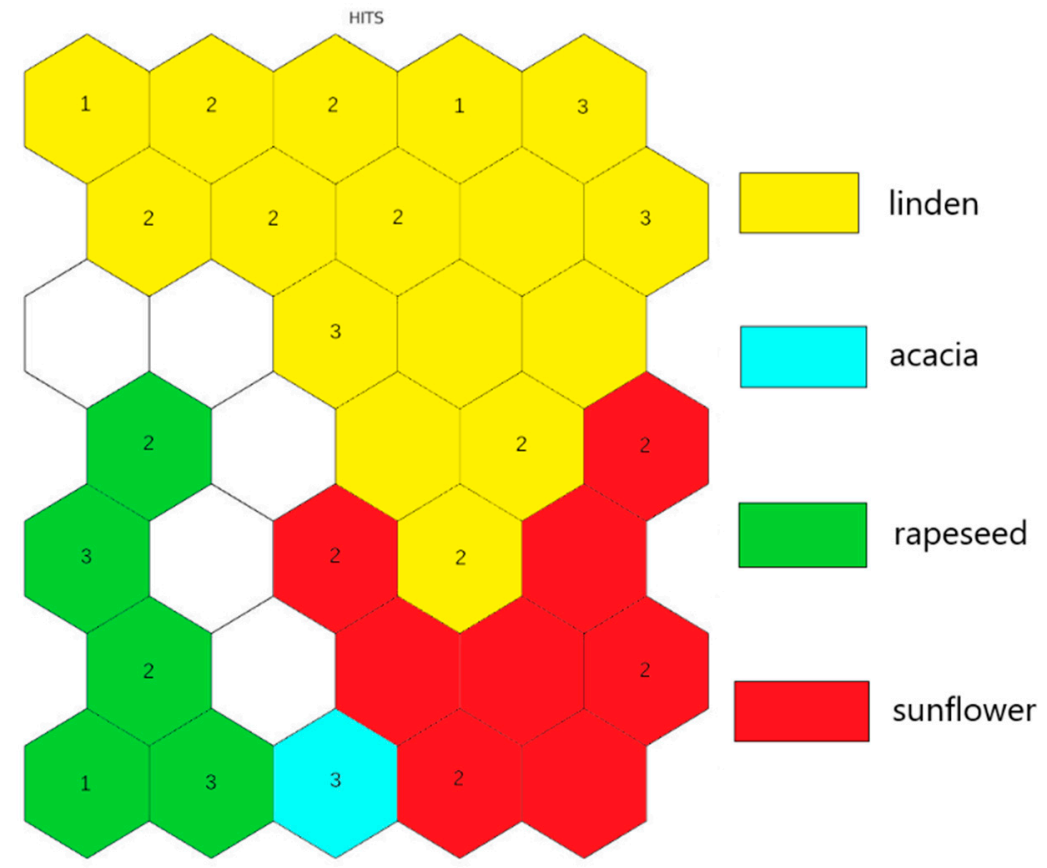

Figure 3. The HIT diagram of training set with the set of descriptors.

\subsection{Botanical Origin Classification}

A new SOM was constructed (Figure 4) with an input layer of all honey samples-the "training" and "testing" sets and the set of sixteen descriptors.

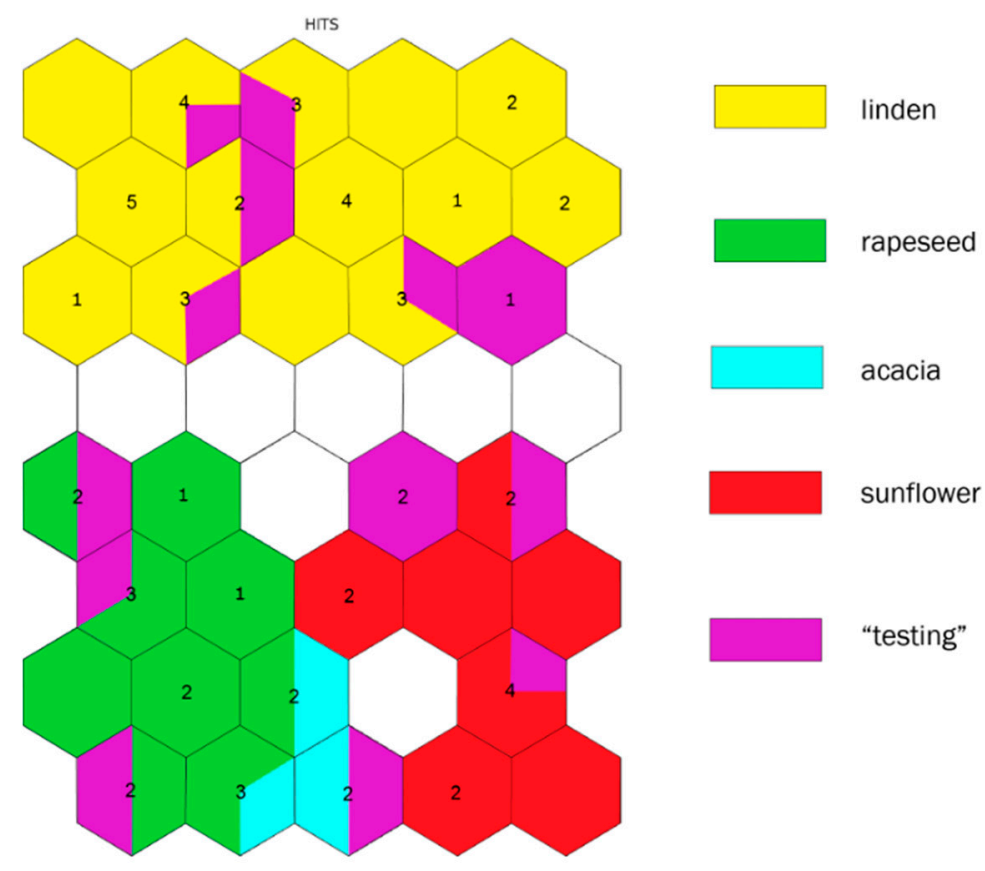

Figure 4. The HIT diagram of training and testing group of honey samples with the set of descriptors.

The linden honey cluster is very well defined - the neurons of this cluster are populated with all linden honey samples from the training set and the six linden honey samples included into the testing group. The ten sunflower honey samples are also separated in another cluster, eight of which are from the training group, while the other two are from the testing group. The rapeseed honey samples form the third group of samples. This cluster is populated with eleven rapeseed honey samples from the training set, three rapeseed 
honey samples from the testing set, and two acacia honey samples from the training set. The last acacia honey sample from the training set, along with the acacia honey sample from the testing set, is in the neuron between the neurons of the rapeseed cluster and the sunflower cluster. The acacia honey samples from the training set are located in three different adjacent nodes. There is one more well-defined cluster, populated with two honey samples, described as polyfloral according to the pollen analysis.

\section{Discussion}

Shortly after collecting the honey samples, they were analysed using pollen analysis for the botanical origin confirmation and various methods and procedures were used for determining their physicochemical parameters and element content. One of the sunflower honey samples was dismissed, because the result for the diastase number was equal to seven, which is below the lower limit of eight [7]. According to the melissopalynological analysis, it was proved that two of the honey samples, claimed to be of sunflower origin by the honey producer, were not. The sunflower pollen content was established to be about $25 \%$ and $30 \%$ only, respectively, in the two samples, where according to legislation [9], the sunflower pollen must be equal to or greater than $40 \%$ in order for monofloral sunflower bee honey to be classified as such. In addition, about $30 \%$ of the pollen was established to be from the Fabaceae family. Based on these results, the two honey samples were redefined as polyfloral.

The ICP-MS results showed that the contents of $\mathrm{Ag}$, As, Se, and Te were under the detection limit of the method $(0.0001 \mu \mathrm{g} / \mathrm{kg})$, which is why these elements were dismissed from the honey samples dataset.

As previously mentioned, there were only four acacia samples available for use-two from 2018 and two from 2019-which was not enough to perform deep chemometric analysis. However, three of the samples were included in the training set and one in the testing set of samples. The results cannot be accepted as reliable, but they could be a good starting point for future studies.

The procedure for constructing the set of descriptors started with training a SOM with an input layer of 47 confirmed monofloral bee honey samples and all 35 variables (9 physicochemical parameters and 26 elements). The HIT diagram (Figure 1) showed an excellent separation by botanical origin into four clusters. The elements $\mathrm{B}, \mathrm{Ca}$, and $\mathrm{Cs}$ were separated from all other variables into two different clusters. The element B was alone in its cluster and, due to this specific behaviour it was included in the final set of descriptors. The second cluster, populated with $\mathrm{Ca}$ and Cs, was also characterised by a specific location, which was a sign of a similar distribution of these parameters into the honey samples. The other clusters of variables were populated with many parameters showing a similar distribution.

The step-by-step reduction of variables started by dismissing a random parameter from the big clusters, e.g., $\mathrm{Ca}$ from a $(\mathrm{Ca}, \mathrm{Cs})$ cluster; $\mathrm{Li}$ from a (Al, $\mathrm{Ba}, \mathrm{Cd}, \mathrm{Cu}, \mathrm{Ga}, \mathrm{K}$, $\mathrm{Li}, \mathrm{Sr}, \mathrm{V}$, Invert, $\mathrm{pH}$ ) cluster; $\mathrm{Mn}$ from the next one, and so on, until the last cluster. After every step of the reduction, the separation by the botanical origin of samples was checked. If the separation was unsuccessful, the reduction step was reversed, and a new variable was excluded from the input layer. This procedure was repeated tens of times until the formation of the final set of 16 descriptors.

The testing set of honey samples consisted of one acacia honey sample, six linden samples, two sunflower samples, three rapeseed samples, and two polyfloral honey samples, confirmed by the melissopalynological analysis. As a result, the linden, sunflower, and rapeseed honey samples from the testing set populated the linden, sunflower, and rapeseed clusters formed by the linden, sunflower, and rapeseed honey samples from the training set, respectively. Only the separation of the acacia honey samples was spoiled, which was attributed to the small number of acacia samples used in the study (four in total). One of the acacia training samples and the acacia sample from the testing set, ended 
up together in one neuron, while the other two acacia samples from the training set were included in two different neurons of the rapeseed cluster.

The polyfloral honey samples were separated in a different cluster unassociated with the other monofloral clusters.

\section{Materials and Methods}

\subsection{Chemicals and Reagents}

All reagents used were of analytical-reagent grade and all aqueous solutions were prepared with MilliQ water (MilliporeCorp., Milford, MA, USA). The stock standard solutions were CertiPUR ${ }^{\circledR}$ ICP Multi-element Standard Solution IV (23 elements in diluted nitric acid), Merck Millipore, $1000 \mathrm{mg} / \mathrm{L}$; and CertiPUR ${ }^{\circledR}$ Reference material GF AAS Multi Element Standard Solution XVIII, Merck Millipore, $100 \mathrm{mg} / \mathrm{L}$. The working standard solutions were prepared weekly through appropriate dilutions. Concentrated $\mathrm{HNO}_{3}(65 \%$, Suprapur, Merck, Kenilworth, NJ, USA) was used for the wet digestion of honey.

\subsection{Melissopalynological Analysis}

The botanical origin of the honey samples was confirmed by melissopalynological analysis, also known as pollen analysis. The pollen analysis was carried out according to the procedures of national legislation $[9,31]$.

\subsection{Physicochemical Analysis}

Nine physicochemical parameters including colour (Col), electrical conductivity (Cond), diastase activity (Diast), hydroxymethylfurfural (HMF), invertase activity (Invert), acidity ( $\mathrm{pH})$, proline (Prol), specific rotation (Rot), and water content (Water), were determined [29,32]. The colour of the honey was determined with a Lovibond Honey ColorPod, UK, and presented in $\mathrm{mm}$ Pfund. The parameters of water content, hydroxymethylfurfural content, electrical conductivity, specific optical rotation, invertase activity, and proline were determined according to the procedure in [32]. Diastase activity and $\mathrm{pH}$ were determined according to the methods described in the Bulgarian State Standard [31].

\subsection{Analysis of Chemical Elements}

\subsubsection{Sample Preparation Procedure}

The preparation of the honey samples was performed according to the procedure reported by other authors [33]. Accurately weighed honey samples (1.0000 $\pm 0.0002 \mathrm{~g})$ were placed in the PTFE vessels of a microwave digestion system (Ethos Easy, Milestone, Milan, Italy), and $9 \mathrm{~mL}$ of $65 \% \mathrm{HNO}_{3}$ and $2 \mathrm{~mL}$ of $30 \% \mathrm{H}_{2} \mathrm{O}_{2}$ were added. The vessels were then left for an hour to cool down, after which they were sealed and placed in the rotor of a microwave oven. The digestion was carried out following the program of 1200 $\mathrm{W} / 20 \mathrm{~min}$ at $120^{\circ} \mathrm{C}, 1200 \mathrm{~W} / 15 \mathrm{~min}$ at $170{ }^{\circ} \mathrm{C}$, and $20 \mathrm{~min}$ of ventilation. The vessels were cooled down to room temperature. Samples were quantitatively transferred into centrifuge tubes and filled up to $15.0000 \pm 0.0002 \mathrm{~g}$ using an analytical balance with MilliQ water. Blank samples were passed through the whole procedure.

\subsubsection{Apparatus}

The contents of thirty elements were measured using an inductively coupled plasma optical emission spectrometer ( Ultima 2, Jobin Yvon, Edison, NJ, USA) and an inductively coupled plasma mass spectrometer (ICP-MS 7900, Agilent, Santa Clara, CA, USA ): Ag, $\mathrm{Al}$, As, B, Ba, Bi, Ca, Cd, Co, Cr, Cs, Cu, Fe, Ga, In, K, Li, Mg, Mn, Na, Ni, P, Pb, Rb, S, Se, $\mathrm{Sr}, \mathrm{Te}, \mathrm{V}$, and $\mathrm{Zn}$. Some of the elements ( $\mathrm{Al}, \mathrm{Ba}, \mathrm{Cr}, \mathrm{Cu}$, and $\mathrm{Fe}$ ) were analysed using both techniques, to ensure the validity of the results. Additionally, the results for $\mathrm{Li}$ and $\mathrm{Rb}$ were confirmed using flame atomic absorption spectrometry.

Inductively coupled plasma optical emission spectrometry (ICP-OES) was used for the determination of elements with a concentration in $\mathrm{mg} / \mathrm{kg}$. The optimized instrumental parameters are presented in Tables 1 and 2. 
Table 1. Optimized instrumental parameters for ICP-OES measurements.

\begin{tabular}{cc}
\hline Generator power & $1.00 \mathrm{~kW}$ \\
\hline Type of nebulizer & V-groove \\
\hline Plasma gas (argon) & $15 \mathrm{~L} / \mathrm{min}$ \\
\hline Cooling gas & $1.50 \mathrm{~L} / \mathrm{min}$ \\
\hline Gas of nebulizer & $1.40 \mathrm{kPa}$ \\
\hline Observation time & $5 \mathrm{~s}$ \\
\hline Burner height & $5 \mathrm{~mm}$ \\
\hline Pump speed & $30 \mathrm{rpm}$ \\
\hline Sample input time & $12 \mathrm{~s}$ \\
\hline Time for stabilization & $15 \mathrm{~s}$ \\
\hline Number of cues & 5 \\
\hline
\end{tabular}

Table 2. Spectral lines for measuring elements by ICP-OES.

\begin{tabular}{cccc}
\hline Element & Spectral Line & Element & Spectral Line \\
\hline $\mathrm{Al}$ & $396.152 \mathrm{~nm}$ & $\mathrm{Mn}$ & $257.610 \mathrm{~nm}$ \\
\hline $\mathrm{Ba}$ & $455.403 \mathrm{~nm}$ & $\mathrm{Na}$ & $588.995 \mathrm{~nm}$ \\
\hline $\mathrm{Ca}$ & $370.602 \mathrm{~nm}$ & $\mathrm{P}$ & $213.618 \mathrm{~nm}$ \\
\hline $\mathrm{Cu}$ & $324.754 \mathrm{~nm}$ & $\mathrm{~S}$ & $181.972 \mathrm{~nm}$ \\
\hline $\mathrm{Fe}$ & $238.204 \mathrm{~nm}$ & $\mathrm{Sr}$ & $407.771 \mathrm{~nm}$ \\
\hline $\mathrm{K}$ & $766.491 \mathrm{~nm}$ & $\mathrm{Zn}$ & $213.857 \mathrm{~nm}$ \\
\hline $\mathrm{Mg}$ & $279.553 \mathrm{~nm}$ & & \\
\hline
\end{tabular}

External calibration by a multi-element standard solution was performed. The square of the correlation coefficients $\left(R^{2}\right)$ for all calibration curves was at least 0.998. Multielement standard solution of $\mathrm{Al}, \mathrm{Ba}, \mathrm{Ca}, \mathrm{Cu}, \mathrm{Fe}, \mathrm{K}, \mathrm{Mg}, \mathrm{Mn}, \mathrm{Na}, \mathrm{S}, \mathrm{Sr}$, and $\mathrm{Zn}$ (ICP Multi-element Standard Solution IV, CertiPUR, Supelco, Bellefonte, PA, USA) with an initial concentration of $1000 \mathrm{mg} / \mathrm{L}$ for each and single element standard solutions of $\mathrm{P}$ (TraceCERT, Supelco, Bellefonte, PA, USA) and S (TraceCERT, Supelco, Bellefonte, PA, USA) with initial concentrations of $1000 \mathrm{mg} / \mathrm{L}$, were mixed and used for calibration after appropriate dilution to obtain the following concentrations: 1.0, 5.0, 10, 20, and $30 \mathrm{mg} / \mathrm{L}$ for $\mathrm{P}$ and $\mathrm{S}$, and $0.2,0.5,1.0,2.0$, and $5.0 \mathrm{mg} / \mathrm{L}$ for the other elements. All solutions were prepared with MilliQ water (MilliporeCorp., Milford, MA, USA). For stabilization of the standard solutions, ultrapure nitric acid $\left(\geq 69.0 \% \mathrm{HNO}_{3}\right.$, TraceSELECT, Honeywell Fluka, Charlotte, NC, USA) was used.

Inductively coupled plasma with mass spectrometric detection (ICP-MS) was used for determining chemical elements with a concentration in $\mu \mathrm{g} / \mathrm{kg}$. Table 3 presents the established instrumental parameters for reaching the maximum signal/noise ratio and meeting the requirements for reliable ICP-MS measurement. Table 4 presents the optimal conditions selected for ICP-MS measurements.

External calibration by a multi-element standard solution was performed. The square of the correlation coefficients $\left(R^{2}\right)$ for all calibration curves was at least 0.99. A multielement standard solution of 30 elements (ICP Multi-element Standard Solution VI, CertiPUR, Supelco, Bellefonte, PA, USA) with an initial concentration of $10 \mathrm{mg} / \mathrm{L}$ for $\mathrm{Ag}$, Ba, $\mathrm{Cd}, \mathrm{Co}, \mathrm{Cr}, \mathrm{Cu}, \mathrm{Ga}, \mathrm{Li}, \mathrm{Ni}, \mathrm{Pb}, \mathrm{Rb}$, and $\mathrm{Te}$, and $100 \mathrm{mg} / \mathrm{L}$ for As and $\mathrm{Se}$, and single element standard solutions of Cs (TraceCERT, Supelco, Bellefonte, PA, USA) and In (TraceCERT, Supelco, Bellefonte, PA, USA) with initial concentrations of $1000 \mathrm{mg} / \mathrm{L}$ were mixed and used for calibration after appropriate dilution to obtain the following concentrations: 5.0, 
10, 20, 50, and $100 \mu \mathrm{g} / \mathrm{L}$ for As and Se, and 0.5, 1.0, 2.0, 5.0, and $10 \mu \mathrm{g} / \mathrm{L}$ for the other elements. All solutions were prepared with MilliQ water (MilliporeCorp., Milford, MA, USA). For stabilization of the standard solutions, ultrapure nitric acid $\left(\geq 69.0 \% \mathrm{HNO}_{3}\right.$, TraceSELECT, Honeywell Fluka, Charlotte, NC, USA) was used.

Table 3. Instrumental parameters for ICP-MS measurements.

\begin{tabular}{cc}
\hline Generator power & $1.20 \mathrm{~kW}$ \\
\hline Type of nebulizer & Meinhardt (concentric) \\
\hline Plasma gas (argon) & $9 \mathrm{~L} / \mathrm{min}$ \\
\hline Additional gas & $1.35 \mathrm{~L} / \mathrm{min}$ \\
\hline Nebulizer flow & $1.1 \mathrm{~L} / \mathrm{min}$ \\
\hline Pump speed & $20 \mathrm{rpm}$ \\
\hline Time for stabilization & $5 \mathrm{~s}$ \\
\hline Number of cues & 5 \\
\hline Number of scans for cues & 10
\end{tabular}

Table 4. Experimental conditions for ICP-MS measurement.

\begin{tabular}{|c|c|c|c|c|}
\hline Element & $m / z$ & Collision Cell Included & Isobaric Interference & Parallel Analysis \\
\hline $\mathrm{Li}$ & 7 & & & $\begin{array}{l}\text { The concentration is } \\
\text { confirmed by FAAS }\end{array}$ \\
\hline $\mathrm{Al}$ & 27 & Yes & ${ }^{12} \mathrm{C}^{15} \mathrm{~N}^{+},{ }^{13} \mathrm{C}^{14} \mathrm{~N}^{+},{ }^{1} \mathrm{H}^{12} \mathrm{C}^{14} \mathrm{~N}^{+}$ & $\begin{array}{l}\text { The concentration is } \\
\text { confirmed by ICP-OES }\end{array}$ \\
\hline $\mathrm{V}$ & 51 & Yes & $\begin{array}{c}{ }^{34} \mathrm{~S}^{16} \mathrm{O}^{1} \mathrm{H}^{+},{ }^{35} \mathrm{C}^{16} \mathrm{O}^{+},{ }^{38} \mathrm{Ar}^{13} \mathrm{C}^{+} \\
{ }^{36} \mathrm{Ar}^{15} \mathrm{~N}^{+}, 36 \mathrm{Ar}^{14} \mathrm{~N}^{1} \mathrm{H}^{+},{ }^{37} \mathrm{C}^{11} 4 \mathrm{~N}^{+} \\
{ }^{36} \mathrm{~S}^{15} \mathrm{~N}^{+},{ }^{33} \mathrm{~S}^{18} \mathrm{O}^{+},{ }^{34} \mathrm{~S}^{17} \mathrm{O}^{+}\end{array}$ & \\
\hline $\mathrm{Fe}$ & 57 & Yes & $\begin{array}{c}{ }^{40} \mathrm{Ar}^{16} \mathrm{O}^{1} \mathrm{H}^{+},{ }^{40} \mathrm{Ca}^{16} \mathrm{O}^{1} \mathrm{H}^{+} \\
{ }^{40} \mathrm{Ar}^{17} \mathrm{O}^{+},{ }^{38} \mathrm{Ar}^{18} \mathrm{O}^{1} \mathrm{H}^{+},{ }^{38} \mathrm{Ar}^{19} \mathrm{~F}^{+}\end{array}$ & $\begin{array}{l}\text { The concentration is } \\
\text { confirmed by ICP-OES }\end{array}$ \\
\hline Co & 59 & Yes & $\begin{array}{c}{ }^{43} \mathrm{Ca}^{16} \mathrm{O}^{+},{ }^{42} \mathrm{Ca}^{16} \mathrm{O}^{1} \mathrm{H}^{+},{ }^{24} \mathrm{Mg}^{35} \mathrm{Cl}^{+}, \\
{ }^{36} \mathrm{Ar}^{23} \mathrm{Na}^{+},{ }^{40} \mathrm{Ar}^{18} \mathrm{O}^{1} \mathrm{H}^{+}\end{array}$ & \\
\hline $\mathrm{Cr}$ & 52 & Yes & $\begin{array}{c}{ }^{35} \mathrm{Cl}^{16} \mathrm{O}^{1} \mathrm{H}+{ }^{40} \mathrm{Ar}^{12} \mathrm{C}^{+},{ }^{36} \mathrm{Ar}^{16} \mathrm{O}^{+} \\
{ }^{37} \mathrm{Cl}^{15} \mathrm{~N}^{+34} \mathrm{~S}^{18} \mathrm{O}^{+},{ }^{\prime 6} \mathrm{~S}^{16} \mathrm{O}^{+} \\
{ }^{38} \mathrm{Ar}^{14} \mathrm{~N}^{+},{ }^{36} \mathrm{Ar}^{15} \mathrm{~N}^{1} \mathrm{H}^{+},{ }^{35} \mathrm{Cl}^{17} \mathrm{O}^{+}\end{array}$ & $\begin{array}{l}\text { The concentration is } \\
\text { confirmed by ICP-OES }\end{array}$ \\
\hline $\mathrm{Ni}$ & 60 & Yes & ${ }^{44} \mathrm{Ca}^{16} \mathrm{O}^{+},{ }^{23} \mathrm{Na}^{37} \mathrm{Cl}^{+},{ }^{43} \mathrm{Ca}^{16} \mathrm{O}^{1} \mathrm{H}^{+}$ & \\
\hline $\mathrm{Cu}$ & 63 & Yes & $\begin{array}{c}{ }^{31} \mathrm{P}^{16} \mathrm{O}_{2}{ }^{+},{ }^{40} \mathrm{Ar}^{23} \mathrm{Na}^{+},{ }^{47} \mathrm{Ti}^{16} \mathrm{O}^{+}, \\
{ }^{23} \mathrm{Na}^{40} \mathrm{Ca}^{+},{ }^{46} \mathrm{Ca}^{16} \mathrm{O}^{1} \mathrm{H}^{+} \\
{ }^{36} \mathrm{Ar}^{12} \mathrm{C}^{14} \mathrm{~N}^{1} \mathrm{H}^{+},{ }^{14} \mathrm{~N}^{12} \mathrm{C}^{37} \mathrm{Cl}^{+}, \\
{ }^{16} \mathrm{O}^{12} \mathrm{C}^{35} \mathrm{Cl}^{+}\end{array}$ & $\begin{array}{l}\text { The concentration is } \\
\text { confirmed by ICP-OES }\end{array}$ \\
\hline $\mathrm{Ga}$ & 71 & Yes & $\begin{array}{c}{ }^{35} \mathrm{Cl}^{18} \mathrm{O}^{+}{ }^{+}{ }^{37} \mathrm{Cl}^{16} \mathrm{O}^{18} \mathrm{O}^{+} \\
{ }^{37} \mathrm{Cl}^{17} \mathrm{O}_{2}{ }^{+},{ }^{36} \mathrm{Ar}^{35} \mathrm{Cl}^{+},{ }^{38} \mathrm{Ar}^{33} \mathrm{~S}^{+}\end{array}$ & \\
\hline As & 75 & Yes & $\begin{array}{c}{ }^{40} \mathrm{Ar}^{35} \mathrm{Cl}^{+},{ }^{59} \mathrm{Co}^{16} \mathrm{O}^{+} \\
{ }^{36} \mathrm{Ar}^{8} \mathrm{Ar}^{1} \mathrm{H}^{+},{ }^{38} \mathrm{Ar}^{37} \mathrm{Cl}^{+},{ }^{36} \mathrm{Ar}^{39} \mathrm{~K}\end{array}$ & \\
\hline Se & 78 & Yes & ${ }^{40} \mathrm{Ar}^{38} \mathrm{Ar}^{+},{ }^{38} \mathrm{Ar}^{40} \mathrm{Ca}^{+}$ & \\
\hline $\mathrm{Rb}$ & 85 & & & $\begin{array}{l}\text { The concentration is } \\
\text { confirmed by FAAS }\end{array}$ \\
\hline $\mathrm{Cd}$ & 111 & & $\begin{array}{c}{ }^{95} \mathrm{Mo}^{16} \mathrm{O}^{+},{ }^{94} \mathrm{Zr}^{16} \mathrm{O}^{1} \mathrm{H}^{+}, \\
{ }^{39} \mathrm{~K}_{2}{ }^{16} \mathrm{O}_{2}{ }^{1} \mathrm{H}^{+}\end{array}$ & \\
\hline In & 115 & & & \\
\hline Cs & 133 & & & \\
\hline $\mathrm{Ba}$ & 137 & & & $\begin{array}{l}\text { The concentration is } \\
\text { confirmed by ICP-OES }\end{array}$ \\
\hline $\mathrm{Pb}$ & 208 & & & \\
\hline $\mathrm{Bi}$ & 209 & & & \\
\hline
\end{tabular}




\subsection{Chemometrics}

The approach of self-organizing maps (SOMs) or Kohonen maps [34] is a member of the big family of neural networks. The big difference from other neural networks is that SOMs do not need a target output. The SOM consist of two layers: the input layer of neurons (nodes), formed from the real honey samples, presented as $k n$-dimensional vectors (where $k$ is the number of honey samples and $n$ is the number of input variables), and the output layer of neurons, arranged as a two-dimensional map. The output layer is the real SOM; every neuron is presented as an $n$-dimensional vector, where $n$ is the same number as the number of input variables forming the input layer.

The algorithm is based on a "winner-takes-all" approach, where the "winner" is the neuron whose vector matches most closely to the input vector of a given sample. The winner node adjusts its vector weights to match the weights of the vector sample, while the neurons surrounding the winner are also modified to look more like the input vector. The occupation of the nodes with samples and the adjustment of the output vectors is repeated tens of thousands of times.

During the training process, after every iteration, the distances between the input and output data are calculated and compared to each other [34]. Finding the minimal distance marks the end of the training process. The trained map graphically presents the grouping of samples and the distribution of variables, the latter of which is visualised as easy to interpret 2D planes. Plane ordering is done after calculating the correlation between the input parameters. This ordering shows the relationship between the variables and could be used as a variable selection procedure when forming the optimal set of descriptors [35].

In this study, all calculations concerning SOMs were performed by the licensed computing platform MATLAB R2019a, with a free SOM Toolbox 2.0 [36].

Sixty-one honey samples were randomly separated into two sets. The first set of forty-seven samples (i.e., the training set) was used for the descriptors set selection, and the second set of fourteen samples (i.e., the testing set) was used for the testing of the classification process. The testing set consisted of one acacia honey sample, six linden honey samples, two sunflower honey samples, three rapeseed honey samples, and two polyfloral honey samples.

The set of descriptors was selected by reducing the number of input variables (minerals and physicochemical parameters) of the training samples, using the SOM approach, all the while maintaining the good separation by the botanical origin principle in the output layer. The reduction of the variables was performed one by one, tens of times, keeping the "golden rule" of a good separation by botanical origin. If a good separation was not achieved after excluding a given variable, the same parameter was included again, and another one was excluded instead. The reduction procedure was repeated until the final set of descriptors was formed, which gave the best separation by botanical origin and a minimum number of input variables.

Using the descriptors set and both sample sets (training and testing) as an input layer, a SOM was trained, where the samples of the training set were used to identify the nodes specific to a given botanical origin. The honey samples from the testing set, which fell into the node classified by botanical origin, were attached to the same botanical origin.

\section{Conclusions}

Four different kinds of monofloral bee honey (linden, rapeseed, sunflower, and acacia) from Bulgaria were successfully separated using a new approach. The presented method combines the determination of a set of sixteen descriptors-diastase activity, hydroxymethylfurfural content, invertase activity, $\mathrm{pH}$, specific optical rotation, water content, $\mathrm{Al}, \mathrm{B}, \mathrm{Cr}, \mathrm{Cs}, \mathrm{K}, \mathrm{Na}, \mathrm{Ni}, \mathrm{Rb}, \mathrm{V}$, and $\mathrm{Zn}$-with the method of self-organizing maps. The physicochemical parameters included in the descriptors' set are regularly determined, in order to ensure quality control assurance in honey as a food product. The determination of the selected chemical elements in the descriptors' set is a routine practice, and requires com- 
mon instrumental techniques, such as ICP-OES and ICP-MS. The new method performs faster and cheaper analyses than the well-known melissopalynological analysis.

Supplementary Materials: The following are available online at https:/ / www.mdpi.com/article/10 $.3390 /$ molecules26237219/s1. Table S1: The data matrix of physicochemical parameters and minerals in acacia bee honey samples $\left(\mathrm{n}_{2018}=2\right.$ and $\left.\mathrm{n}_{2019}=2\right)$, Table S2: Basic statistics of physicochemical parameters and minerals in linden bee honey samples $\left(\mathrm{n}_{2018}=17\right.$ and $\left.\mathrm{n}_{2019}=14\right)$, Table S3: Basic statistics of physicochemical parameters and minerals in sunflower bee honey samples from 2019 (n $=10$ ), Table S4: Basic statistics of physicochemical parameters and minerals in rapeseed bee honey samples $\left(\mathrm{n}_{2018}=8\right.$ and $\left.\mathrm{n}_{2019}=6\right)$.

Author Contributions: Conceptualization, T.V., E.M. and R.B.; methodology, T.V., E.M. and R.B.; software, T.V.; validation, T.V., E.M. and R.B.; formal analysis, T.V., E.M. and R.B.; investigation, T.V., E.M. and R.B.; resources, T.V., E.M. and R.B.; data curation, T.V.; writing-original draft preparation, T.V., E.M. and R.B.; writing-review and editing, T.V. and E.M.; visualization, T.V.; supervision, T.V. and E.M.; project administration, E.M.; funding acquisition, E.M. All authors have read and agreed to the published version of the manuscript.

Funding: This research was funded by the Ministry of Education and Science, Bulgarian National Science Fund, Grant DM 19/1 and under the National Research Programme "Healthy Foods for a Strong Bio-Economy and Quality of Life", approved by DCM \# 577/17.08.2018.

Institutional Review Board Statement: Not applicable.

Informed Consent Statement: Not applicable.

Data Availability Statement: Not applicable.

Acknowledgments: The authors gratefully acknowledge the financial support from the Bulgarian National Science Fund (Grant DM 19/1). Research equipment of the Distributed Research Infrastructure INFRAMAT, part of the Bulgarian National Roadmap for Research Infrastructures, supported by the Bulgarian Ministry of Education and Science, was used in this investigation.

Conflicts of Interest: The authors declare no conflict of interest.

\section{References}

1. Bogdanov, S.; Haldimann, M.; Luginbühl, W.; Gallmann, P. Minerals in honey: Environmental, geographical and botanical aspects. J. Apic. Res. 2007, 46, 269-275. [CrossRef]

2. Saitta, M.; Di Bella, G.; Fede, M.R.; Lo Turco, V.; Potortì, A.G.; Rando, R.; Russo, M.T.; Dugo, G. Gas chromatography-tandem mass spectrometry multi-residual analysis of contaminants in Italian honey samples. Food Addit. Contam. A 2017, 34, 800-808.

3. Ramón-Sierra, J.M.; Ruiz-Ruiz, J.C.; de la Luz Ortiz-Vázquez, E. Electrophoresis characterisation of protein as a method to establish the entomological origin of stingless bee honeys. Food Chem. 2015, 183, 43-48. [CrossRef]

4. Oddo, L.P.; Piro, R.R. Extra issue of European unifloral honeys. Apidologie 2004, 35, S38-S81.

5. Fodor, P.; Molnar, E. Honey as an environmental indicator: Effect of sample preparation on trace element determination by ICP-AES. Mikrochim. Acta 1993, 112, 113-118. [CrossRef]

6. Anklam, E. A review of the analytical methods to determine the geographical and botanical origin of honey. Food Chem. 1998, 63, 549-562. [CrossRef]

7. Council Directive 2001/110/EC of the 20 December 2001 relating to honey. Off. J. Eur. Commun. 2002, 10, 47-52. Available online: https:/ / eur-lex.europa.eu/legal-content/EN/TXT/PDF/?uri=CELEX:32001L0110\&from=EN (accessed on 26 November 2021).

8. Louveaux, J.; Maurizio, A.; Vorwohl, G. Methods of melissopalynology. Bee World 1978, 59, 139-157. [CrossRef]

9. Bulgarian State Standard-BDS 2673, Bee Honey, 1989. Available online: https://bds-bg.org/en/project/show/bds:proj:22569 (accessed on 26 November 2021).

10. Zhang, X.; Zhang, S.; Qing, X.; Lu, Z. A new strategy for rapid classification of honeys by simple cluster analysis method based on combination of various physicochemical parameters. Chem. J. Chin. Univ. 2019, 35, 390-394. [CrossRef]

11. Dżugan, M.; Tomczyk, M.; Sowa, P.; Grabek-Lejko, D. Antioxidant activity as biomarker of honey variety. Molecules 2018, 23, 2069. [CrossRef]

12. Roshan, A.-R.A.; Gad, H.A.; El-Ahmady, S.H.; Abou-Shoer, M.I.; Khanbash, M.S.; Al-Azizi, M.M. Characterization and discrimination of the floral origin of sidr honey by physicochemical data combined with multivariate analysis. Food Anal. Method 2017, 10, 137-146. [CrossRef]

13. Adgaba, N.; Al-Ghamdi, A.A.; Getachew, A.; Tadesse, Y.; Belay, A.; Ansari, M.J.; Radloff, S.E.; Sharm, D. Characterization of honeys by their botanical and geographical origins based on physico-chemical properties and chemo-metrics analysis. J. Food Meas. Charact. 2017, 11, 1106-1117. [CrossRef] 
14. Sogut, E.; Seydim, A.C. Classification of honeys collected from different regions of Anatolia by chemometric methods. J. Food Process. Preserv. 2020, 44, e14960. [CrossRef]

15. Rosiak, E.; Madras-Majewska, B.; Teper, D.; Łepecka, A.; Zielińska, D. Cluster analysis classification of honey from two different climatic zones based on selected physicochemical and of microbiological parameters. Molecules 2021, 26, 2361. [CrossRef] [PubMed]

16. Majewska, E.; Druzyńska, B.; Wołosiak, R. Determination of the botanical origin of honeybee honeys based on the analysis of their selected physicochemical parameters coupled with chemometric assays. Food Sci. Biotechnol. 2019, 28, 1307-1314. [CrossRef] [PubMed]

17. Chen, H.; Jin, L.; Chang, Q.; Peng, T.; Hu, X.; Fan, C.; Pang, G.; Lu, M.; Wang, W. Discrimination of botanical origins for Chinese honey according to free amino acids content by HPLC-FLD with chemometric approaches. J. Sci. Food Agric. 2016, 97, 2042-2049. [CrossRef]

18. Silva, B.; Gonzaga, L.V.; Maltez, H.F.; Samochvalov, K.B.; Fett, R.; Costa, A.C.O. Elemental profiling by ICP-MS as a tool for geographical discrimination: The case of bracatinga honeydew honey. J. Food Compos. Anal. 2021, 96, 103727-103735. [CrossRef]

19. Castiglioni, S.; Stefano, M.; Pisani, M.; Carloni, P. Geographical characterisation of multifloral honeys from the Marche region (Italy) according to their antioxidant activity and colour using a chemometric approach. Int. J. Food Sci. Technol. 2018, 53, 571-581. [CrossRef]

20. Drivelos, S.A.; Danezis, G.P.; Halagarda, M.; Popek, S.; Georgiou, C.A. Geographical origin and botanical type honey authentication through elemental metabolomics via chemometrics. Food Chem. 2021, 338, 127936-127943. [CrossRef]

21. Brugnerotto, P.; Silva, B.; Seraglio, S.K.T.; Schulz, M.; Blainski, E.; Dortzbach, D.; Gonzaga, L.V.; Fett, R.; Costa, A.C.O. Physicochemical characterization of honeys from Brazilian monitored beehives. Eur. Food Res. Technol. 2021, $247,2709-2719$. [CrossRef]

22. Kaczmarek, A.M.; Muzolf-Panek, M.; Tomaszewska-Gras, J.; Konieczny, P. Predicting the botanical origin of honeys with chemometric analysis according to their antioxidant and physicochemical properties. Pol. J. Food Nutr. Sci. 2019, 69, 191-201. [CrossRef]

23. Maione, C.; Barbosa Jr., F.; Barbosa, R.M. Predicting the botanical and geographical origin of honey with multivariate data analysis and machine learning techniques: A review. Comput. Electron. Agric. 2019, 157, 436-446. [CrossRef]

24. Machado, A.M.; Antunes, M.; Miguel, M.G.; Vilas-Boas, M.; Figueiredo, A.C. Volatile profile of Portuguese monofloral honeys: Significance in botanical origin determination. Molecules 2021, 26, 4970. [CrossRef] [PubMed]

25. Zhao, Z.; Chen, L.; Liu, F.; Zhou, F.; Peng, J.; Sun, M. Fast classification of geographical origins of honey based on laser-induced breakdown spectroscopy and multivariate analysis. Sensors 2020, 20, 1878. [CrossRef] [PubMed]

26. Azevedo, M.S.; Seraglio, S.K.T.; Rocha, G.; Balderas, C.B.; Piovezan, M.; Gonzag, L.V.; de Barcellos Falkenberg, D.; Fett, R.; de Oliveira, M.A.L.; Costa, A.C.O. Free amino acid determination by GC-MS combined with a chemometric approach for geographical classification of bracatinga honeydew honey (Mimosa scabrella Bentham). Food Control 2017, 78, 383-392. [CrossRef]

27. Ghidotti, M.; Fiamegos, Y.; Dumitrascu, C.; de la Calle, M.B. Use of elemental profiles to verify geographical origin and botanical variety of Spanish honeys with a protected denomination of origin. Food Chem. 2021, 342, 128350-128361. [CrossRef]

28. Tananaki, C.; Thrasyvoulou, A.; Giraudel, J.L.; Montury, M. Determination of volatile characteristics of Greek and Turkish pine honey samples and their classification by using Kohonen self organising maps. Food Chem. 2007, 101, 1687-1693. [CrossRef]

29. De Boishebert, V.; Giraudel, J.-L.; Montury, M. Characterization of strawberry varieties by SPME-GC-MS and Kohonen selforganizing map. Chemom. Intel. Lab. 2006, 80, 13-23. [CrossRef]

30. Dinkov, D. Quality parameters of Bulgarian kinds of bee honey. Maced. Vet. Rev. 2014, 37, 35-41. [CrossRef]

31. Bulgarian State Standard-BDS 3050, Bee Honey. Rules for Sampling and Testing Methods, 1980. Available online: https: / / bds-bg.org/en/project/show / bds:proj:22905 (accessed on 26 November 2021).

32. Bogdanov, S.; Martin, P.; Lullmann, C.; Borneck, R.; Flamini, C.; Morlot, M.; Lheritier, J.; Vorwohl, G.; Russmann, H.; Persano, L.; et al. Harmonized methods of the European Honey commission. Apidologie 1997, 28, 1-59.

33. Chudzinska, M.; Baralkiewicz, D. Application of ICP-MS method of determination of 15 elements in honey with chemometric approach for the verification of their authenticity. Food Chem. Toxicol. 2011, 49, 2741-2749. [CrossRef]

34. Kohonen, T. Self-Organization and Associative Memory; Springer: Berlin/Heidelberg, Germany, 1984; pp. $1464-1480$.

35. Voyslavov, T.; Tsakovski, S.; Simeonov, V. Surface water quality assessment using self-organizing maps and Hasse diagram technique. Chemom. Intel. Lab. 2012, 118, 280-286. [CrossRef]

36. Vesanto, J. SOM-based data visualization methods. Intel. Data Anal. 1999, 3, 111-126. [CrossRef] 